\title{
Влияние ионизирующего облучения на распределение зарядов и пробой МОП-транзисторов
}

\author{
(C) О.В. Александров ${ }^{1,2}$, Н.С. Тяпкин ${ }^{2}$, С.А. Мокрушина ${ }^{1,2}$, В.Н. Фомин ${ }^{2}$ \\ ${ }^{1}$ Санкт-Петербургский государственный электротехнический университет „ЛЭТИ“, \\ 197376 Санкт-Петербург, Россия \\ ${ }^{2}$ АО „Светлана-Полупроводники“, \\ 194156 Санкт-Петербург, Россия \\ E-mail: Aleksandr_ov@mail.ru
}

Поступила в Редакцию 2 сентября 2021 г.

В окончательной редакции 18 октября 2021 г.

Принята к публикации 18 октября 2021 г.

\begin{abstract}
Исследовано влияние ионизирующего облучения на образование зарядов на внутренней $\mathrm{SiO}_{2}-\mathrm{Si}$ (подложка) и внешней $\mathrm{SiO}_{2}-\mathrm{Si}_{\mathrm{ps}}$ (затвор) межфазных границах (МФГ) и на пробой затвора МОП-транзисторов. Показано, что с увеличением дозы ионизирующего облучения вблизи внутренней межфазной границы в $p$ - МОП-транзисторах наблюдается монотонный рост положительного заряда, а в $n$ - МОП-транзисторах накопление сначала положительного, а при дозах свыше $10^{5}$ рад - отрицательного заряда. Вблизи внешней межфазной границы при малых дозах облучения наблюдается накопление положительного заряда, а при дозах $>10^{6}$ рад - накопление отрицательного заряда как в $p$-, так и $n$ - МОП-транзисторах. Вплоть до дозы $10^{8}$ рад ионизирующее облучение не оказывает заметного влияния на напряжение пробоя затвора как в $p$-, так и в $n$ - МОП-транзисторах при обеих полярностях смещения. Отсутствие влияния объясняется пробоем по механизму анодной дырочной инжекции.
\end{abstract}

Ключевые слова: ионизирующее облучение, МОП-транзистор, накопление заряда, пробой затвора.

DOI: 10.21883/FTP.2022.02.51970.9735

\section{1. Введение}

Известно, что при ионизирующем облучении (ИО) в подзатворном диэлектрике МОП-транзисторов образуется объемный и поверхностный заряды $[1,2]$. Объемный заряд располагается вблизи кремниевой подложки и связывается с кислородными вакансиями в $\mathrm{SiO}_{2}$. Поверхностный заряд располагается на внутренней межфазной границе $\mathrm{SiO}_{2}-\mathrm{Si}$ (подложка) и связывается с так называемыми $P_{b}$-центрами. Эти наведенные при ИО заряды оказывают значительное влияние на характеристики МОП-транзисторов - пороговое напряжение, крутизну сток-затворных характеристик, подвижность носителей в канале [3,4]. Менее изучено образование при ИО заряда на внешней МФГ с поликремниевым затвором $\mathrm{SiO}_{2}-\mathrm{Si}_{\mathrm{ps}}$, поскольку он не оказывает заметного влияния на указанные характеристики МОП-транзисторов. Однако этот заряд может приводить к изменению напряженности внутреннего электрического поля и тем самым влиять на напряжение пробоя затвора.

В настоящей работе исследуются накопление зарядов при ИО как на внутренней, так и на внешней МФГ в $p$ и $n$-канальных МОП-транзисторах с поликремниевым затвором и их влияние на пробивное напряжение затвора.

\section{2. Описание эксперимента}

Исследовались $n$ - и $p$-канальные МОП-транзисторы, изготовленные по стандартной планарной технологии на кремниевых структурах с диэлектрической изоляцией в карманах $p$ - и $n$-типа соответственно. Подзатворным диэлектриком являлся диоксид кремния $\mathrm{SiO}_{2}$ толщиной 0.12 мкм, полученный термическим окислением кремния при температуре $1000^{\circ} \mathrm{C}$ в сухом кислороде. В качестве затвора использовался слой поликремния $\left(\mathrm{Si}_{\mathrm{ps}}\right)$ толщиной 0.5 мкм, легированный фосфором. Контакты формировались путем вжигания алюминия после его напыления и фотолитографии.

Облучение МОП-транзисторов производилось на $\gamma$-облучателе твердотельных изделий (ГОТ), содержащем радионуклид ${ }^{137} \mathrm{Cs}$ c мощностью излучения $62.5 \mathrm{paд} / \mathrm{c}$ в течение времени от $16 \mathrm{c}$ до 18 дней, что соответствовало диапазону доз ИО от $10^{3}$ до $10^{8}$ рад.

Для определения наведенного ИО заряда, приведенного к внутренней границе раздела $\mathrm{SiO}_{2}-\mathrm{Si}$ (подложка) $\left(Q_{t}\right)$, проводились измерения сдвига порогового напряжения транзисторов $\left(V_{\text {th }}\right)$ до и после ИО на уровне тока стока 10 мкА: $Q_{t}=\Delta V_{\mathrm{th}} C_{o x} / q$, где $\Delta V_{\mathrm{th}}-$ сдвиг (изменение) порогового напряжения, $C_{o x}-$ удельная емкость оксида, $C_{o x}=\varepsilon_{o x} \varepsilon_{0} / d_{o x} ; d_{o x}-$ толщина подзатворного оксида, $q$ - заряд электрона; $\varepsilon_{o x}-$ относительная диэлектрическая проницаемость диоксида кремния $\left(\varepsilon_{o x}=3.9\right), \varepsilon_{0}$ - электрическая постоянная.

Для определения наведенного ИО заряда, приведенного к внешней границе раздела $\mathrm{SiO}_{2}-\mathrm{Si}_{\mathrm{ps}}$ (затвор) $\left(Q_{g}\right)$, проводились измерения сдвига напряжения затвора транзисторов $\left(V_{g}\right)$ до и после ИО на уровне тока $1 \mathrm{HA}$ (сток и исток заземлены на подложку): $Q_{g}=\Delta V_{g} C_{o x} / q$, где $\Delta V_{g}$ - сдвиг напряжения затвора. 
Измерение пробивного напряжения затвора $\left(V_{b}\right)$ проводилось путем плавной подачи на затвор напряжения относительно подложки (сток и исток МОП-транзисторов соединялись с подложкой) со скоростью $\sim 10 \mathrm{~B} / \mathrm{c}$ вплоть до резкого увеличения тока до уровня 1 мкА. При каждой дозе ИО измерялось не менее чем по 10 и $n$-канальных МОП-транзисторов на пластине в обеих полярностях и определялись средние значения.

\section{3. Экспериментальные результаты}

Зависимость плотности заряда, приведенного к внутренней границе раздела $\mathrm{SiO}_{2}-\mathrm{Si}$ (подложка), для $n$ - и $p$-канальных МОП-транзисторов от дозы ИО показана на рис. 1. Как видно из рисунка, в $p$-канальных МОП-транзисторах (значки 1) наблюдается монотонное увеличение положительного заряда, тогда как в $n$-канальных МОП-транзисторах (значки 2) увеличение положительного заряда наблюдается только до дозы $10^{5}$ рад. При дальнейшем увеличении дозы в $n$ - МОП-транзистоpax происходит появление и рост отрицательного заряда.

Зависимость плотности заряда, приведенного к внешней границе, раздела $\mathrm{SiO}_{2}-\mathrm{Si}_{\mathrm{ps}}$ (затвор) для $n$ - и $p$-канальных МОП-транзисторов от дозы ИО показана на рис. 2. Как видно из рисунка, с увеличением дозы до $10^{6}$ рад как в $p$-канальных (значки 1 ), так и в $n$-канальных (значки 2) МОП-транзисторах сначала наблюдается рост положительного заряда. При дальнейшем увеличении дозы наблюдается появление и рост отрицательного заряда.

Результаты измерения пробивного напряжения затворов $n$ - и $p$-канальных МОП-транзисторов приведены на рис. 3. Как видно из рисунка, в пределах разброса

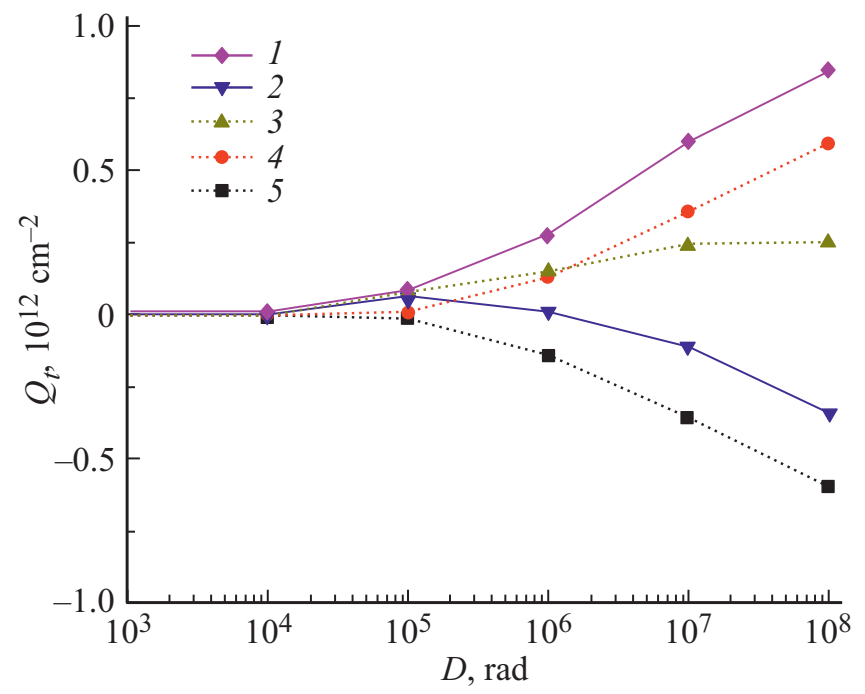

Рис. 1. Зависимость зарядов на внутренней $\mathrm{MФГ} \mathrm{SiO}_{2}-\mathrm{Si}$ (подложка) от дозы ИО: $1-Q_{t p}$ для $p$ - МОП-транзисторов, $2-Q_{t n}$ для $n$ - МОП-транзисторов, $3-Q_{o t p}=Q_{o t n}$ для $n$ и $p$ - МОП-транзисторов, $4-Q_{i t p}$ для $p$ - МОП-транзисторов, $5-Q_{i t n}$ для $n$ - МОП-транзисторов.

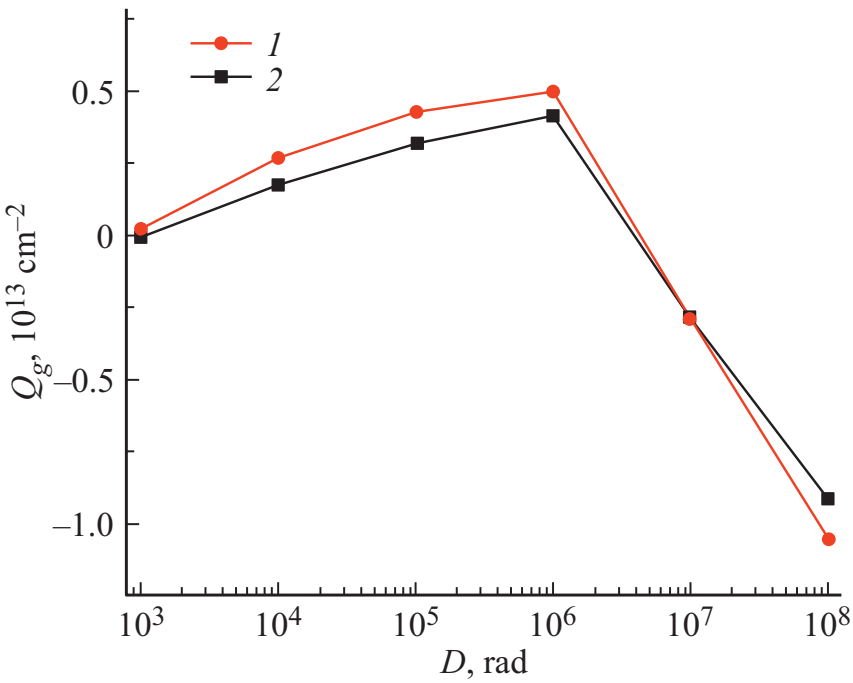

Рис. 2. Зависимость зарядов на внешней МФГ $\mathrm{SiO}_{2}-\mathrm{Si}_{\mathrm{ps}}$ (затвор) от дозы ИО: $1-Q_{g p}$ для $p$ - МОП-транзисторов, $2-Q_{g n}$ для $n$ - МОП-транзисторов.

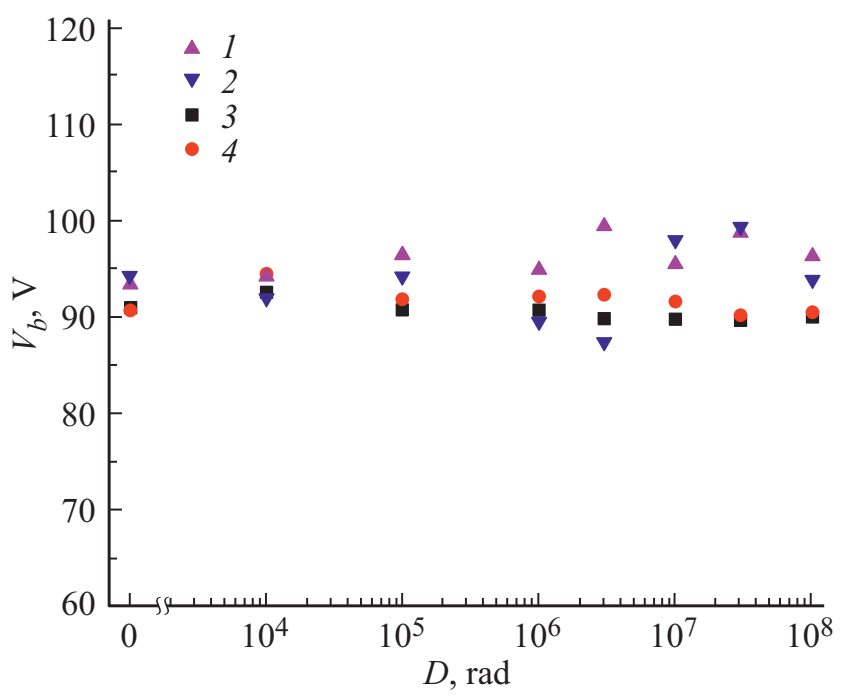

Рис. 3. Зависимость напряжения пробоя затвора от дозы ИО: 1,2 - $p$ - МОП-транзисторы; 3,4 $-n$ - МОП-транзисторы; 1,3 - полярность $\left(+V_{g}\right) ; 2,4-$ полярность $\left(-V_{g}\right)$.

измерений (не более $4 \%$ ) ИО не оказывает заметного влияния на напряжение пробоя затвора как в $p$-, так и в $n$ - МОП-транзисторах, как при положительном, так и при отрицательном смещениях вплоть до максимальной используемой дозы $10^{8}$ рад.

\section{4. Обсуждение результатов}

Разное поведение введенного ИО заряда, приведенного к внутренней границе раздела $\mathrm{SiO}_{2}-\mathrm{Si}$ (подложка), для $n$ - и $p$-канальных МОП-транзисторов на рис. 1 объясняется разными знаками поверхностной составляющей заряда $\Delta Q_{i t}$ - отрицательной для $n$-канальных и по- 
ложительной для $p$-канальных МОП-транзисторов. Это связано с тем, что поверхностные состояния обусловлены амфотерными $P_{b}$-центрами, принимающими заряд, соответствующий типу легирования кремниевой подложки $[1,2]$. Осуществлялось разделение заряда, введенного ИО, на поверхностную и объемную составляющие по методу транзисторной пары [5] для $n$ - и $p$-канальных МОП-транзисторов, изготовленных в одном технологическом цикле. При одинаковом относительном падении подвижности электронов в $n$-канальных и дырок в $p$-канальных МОП-транзисторах под действием ИО имеем:

$$
\begin{gathered}
Q_{o t p}=Q_{o t n} \cong\left(Q_{t p}+Q_{t n}\right) / 2, \\
Q_{i t p} \cong-Q_{i t n} \cong\left(Q_{t p}-Q_{t n}\right) / 2,
\end{gathered}
$$

где $Q_{o t p}$ и $Q_{o t n}$ - объемные составляющие заряда, наведенного ИО, в $p$ - и $n$-канальных МОП-транзисторах соответственно; $Q_{i t p}$ и $Q_{i t n}-$ поверхностные составляющие заряда, наведенного ИО, в $p$ - и $n$-канальных МОП-транзисторах соответственно. Рассчитанные по (1) и (2) составляющие заряда построены на рис. 1 пунктирными кривыми. При дозах $>10^{5}$ рад поверхностный заряд (кривые 4,5) начинает превосходить объемный (кривая 3), что объясняет наблюдаемый рост отрицательного заряда в $n$-канальных МОП-транзисторах.

Поведение введенного ИО заряда, приведенного к внешней границе раздела $\mathrm{SiO}_{2}-\mathrm{Si}_{\mathrm{ps}}$ (затвор), на рис. 2 можно объяснить тем, что при дозах до $10^{6}$ рад преобладает захват дырок на дырочные ловушки, поскольку концентрация дырок при ИО значительно выше, чем электронов. При дальнейшем увеличении дозы все дырочные ловушки заполняются и начинает преобладать захват электронов на электронные ловушки вблизи поликремниевого затвора, концентрация которых может быть выше, чем дырочных.

Как показано на рис. 3, ИО не оказывает заметного влияния на напряжение пробоя затвора в широком диапазоне доз от $10^{3}$ до $10^{8}$ рад как в $p$-, так и в $n$ МОП-транзисторах, как при положительном, так и при отрицательном смещениях. Ранее в работе [6] также наблюдалось отсутствие заметного влияния $\gamma$-облучения ${ }^{60} \mathrm{Co}$ с дозой $17 \mathrm{Mрад} \mathrm{на} \mathrm{пробивное} \mathrm{напряжение}$ МОП-конденсаторов с тонким (8 нм) и толстым (200 нм) диэлектриком $\mathrm{SiO}_{2}$. Относительно слабое влияние дозы $\gamma$-облучения ${ }^{60} \mathrm{Co}$ вплоть до $2 \cdot 10^{6}$ рад на пробивное напряжение пленки диоксида кремния в МОП-структуре наблюдалось и в монографии [3].

Таким образом, накопление зарядов как вблизи внутренней, так и вблизи внешней МФГ, изменяющих локальную напряженность внутреннего электрического поля, не оказывает заметного влияния на пробой подзатворного диэлектрика. Этот результат указывает на то, что пробой происходит не вследствие механизма ударной ионизации в объеме диэлектрика при локальном превышении критической напряженности электрического поля, как считалось ранее [7], а определяется внешней разностью потенциалов. Это в свою очередь указывает на альтернативный механизм пробоя вследствие анодной дырочной инжекции [8,9]. По этому механизму под действием горячих электронов, набравших энергию в диэлектрике в соответствии с напряжением, приложенным к затвору, в материале анода образуются электронно-дырочные пары. Под действием поля дырки инжектируются в диэлектрик и накапливаются на дырочных ловушках у катода, что приводит к положительной обратной связи и пробою. Как показано в работе [9], наличие нейтральных дырочных ловушек оказывает слабое влияние на напряжение пробоя затвора при высоких их концентрациях $\left(>10^{14} \mathrm{~cm}^{-2}\right)$. Это соответствует количеству заряженных ловушек (величине объемного заряда) $\sim 10^{12} \mathrm{~cm}^{-2}$, что в свою очередь примерно соответствует начальному (до ИО) заряду оксида в типовых МОП-транзисторах. При меньших концентрациях нейтральных дырочных ловушек изменение пробивного напряжения вследствие заряжения при ИО дырочных ловушек у затвора $\Delta V_{B R}=-q Q_{T}^{+} / C_{o x}$ компенсируется соответствующим сдвигом напряжения затвора $\Delta V_{g}=+q Q_{o g} / C_{o x}$, где $Q_{o g}$ - эффективный заряд, приведенный к внешней МФГ (к затвору), $Q_{o g}=q \int_{0}^{d} \rho(x / d) d x$. При высокой степени локализации заряда у внешней МФГ $Q_{o g} \cong Q_{T}^{+}$. Сдвиг напряжения под действием поверхностной составляющей заряда при $\Delta V_{g}=q Q_{i t} / C_{o x}$ при $Q \leq 6 \cdot 10^{11} \mathrm{~cm}^{-2}$ (см. рис. 1) не превышает $3 \mathrm{~B}$, что укладывается в разброс данных на рис. 3. Все это позволяет объяснить отсутствие заметного влияния дозы ИО на напряжение пробоя затвора.

\section{5. Заключение}

1. Показано, что с увеличением дозы ИО в $p$-канальных МОП-транзисторах вблизи внутренней МФГ $\mathrm{Si}-\mathrm{SiO}_{2}$ наблюдается монотонный рост положительного заряда, а в $n$-канальных - накопление сначала положительного, а при дозах $>10^{5}$ рад отрицательного зарядов. Результат объясняется разным знаком поверхностной составляющей заряда в $p$ - и $n$-канальных МОП-транзисторах.

2. Вблизи внешней $\mathrm{MФГ} \mathrm{Si}_{\mathrm{ps}}-\mathrm{SiO}_{2}$ при малых дозах облучения наблюдается накопление положительного заряда, а при больших дозах $>10^{6}$ рад - отрицательного заряда как в $p$-, так и $n$ - МОП-транзисторах. Результат объясняется начальным преобладанием захвата дырок на дырочные ловушки, а после их насыщения - захватом электронов на электронные ловушки.

3. Показано, что ИО не оказывает заметного влияния на напряжение пробоя затвора как в $p$-, так и $n$ - МОП-транзисторах, как при положительном, так и при отрицательном смещениях вплоть до дозы $10^{8}$ рад. Результат объясняется пробоем по механизму анодной дырочной инжекции, при котором влияние на пробой заряда дырочных ловушек компенсируется соответствующим сдвигом напряжения затвора. 


\section{Конфликт интересов}

Авторы заявляют об отсутствии конфликта интересов.

\section{Список литературы}

[1] К.И. Таперо, В.Н. Улимов, А.М. Членов. Радиационные эфбекты в кремниевых интегральных схемах космического применения (М., БИНОМ, Лаборатория знаний, 2012).

[2] T.R. Oldham. IEEE Trans. Nucl. Sci., 50, 483 (2003).

[3] В.С. Першенков, В.Д. Попов, А.В. Шальнов. Поверхностные радиационные эффекты в ИМС (М., Энергоатомиздат, 1988).

[4] Ф.П. Коршунов, Ю.В. Богатырев, В.А. Вавилов. Воздействие радиации на интегральные микросхемы (Минск, Наука и техника, 1986).

[5] D.M. Fleetwood. Appl. Phys. Lett., 55, 466 (1989).

[6] A. Paccagnella, A. Candelori, A. Milani, E. Formigoni, G. Ghddini, F. Pellizzer, D. Drera, P.G. Fuochi, M. Lavale. IEEE Trans. Nucl. Sci., 43, 2609 (1996).

[7] N. Klein. Thin Sol. Films, 50, 223 (1978).

[8] M.V. Fischetti. Phys. Rev. B, 31, 2099 (1985).

[9] О.В. Александров. ФТП, 51, 1105 (2017).

Редактор Г.А. Оганесян

\section{Effect of ionizing radiation on charge distribution and breakdown of mosfets}

O.V. Alexandrov ${ }^{1,2}$, N.S. Tyapkin ${ }^{2}$, S.A. Mokrushina ${ }^{1,2}$, V.N. Fomin ${ }^{2}$

${ }^{1}$ St. Petersburg State Electrotechnical University „LETI“, 197376 St. Petersburg, Russia,

${ }^{2}$ AO „Svetlana-Semiconductors“, 194156 St. Petersburg, Russia

Abstract The effect of ionizing radiation on the formation of charges at the internal $\mathrm{SiO}_{2}-\mathrm{Si}$ (substrate) and external $\mathrm{SiO}_{2}-\mathrm{Si}$ (gate) interfacial boundaries and on the gate breakdown of MOSFETs is studied. It is shown that with an increase in the dose of ionizing radiation near the internal interfacial boundaries, a monotonous increase of the positive charge in $p$-MOSFETs, and the accumulation of positive charges at first, and at doses above $10^{5} \mathrm{rad}$ the accumulation of negative charges in $n$-MOSFETs is observed. Near the external interfacial boundaries, at low radiation doses, positive charge accumulation is observed, and at doses above $10^{6} \mathrm{rad}$, negative charge in both $p$ - and $n$-MOSFETs is observed. It is shown that up to a dose of $10^{8}$ rad ionizing radiation does not have a noticeable effect on the gate breakdown voltage in both $p$ - and $n$-MOSFETs at both polarities. The absence of influence is explained by a breakdown by the mechanism of anode hole injection. 